Introduction and Objectives Exacerbations because of COPD are the third largest cause of emergency hospital admissions in the UK. This systematic literature review explored the relationshipbetween hospitalisation rates and the COPD co-morbidities, anxiety and depression.

Methods The Centre for Research Dissemination's framework for systematic reviews was followed using search terms relating to COPD, anxiety, depression and hospital admission. Papers identified were assessed for relevance and quality using a suitable CASP tool and the Mixed Methods Assessment Tool (MMAT).

Results Quantitative studies (18) indicated that anxiety and depression led to a statistically significant increase in the likelihood of COPD patients being hospitalised. These co-morbidities also led to an increased length of stay and a greater risk of mortality post discharge. Other significant factors included lower BODE scores, female gender, lower socioeconomic status, poorer patient perceived quality of life, increased severity of lung function and less improvement in dyspnoea from admission to discharge. It was also highlighted that only $27-33 \%$ of those with depression were being treated for it. Qualitative studies (6), revealed that patients saw anxiety and depression as a major factor that affected their ability to cope with and self-manage their condition.

Implications Findings from the systematic review have highlighted a need for better recognition and treatment of anxiety and depression amongst individuals with COPD. On-going research will develop and test strategies for promoting better management and self-management as a means of reducing hospital admissions.

\section{M19 THE IMPACT OF CO-MORBIDITIES ON PHYSICAL FUNCTION AND HEALTH STATUS IN CHRONIC OBSTRUCTION PULMONARY DISEASE (COPD)}

NS Gale, AM Albarrati, IC Munnery, MM Munnery, JC Cockcroft, DJ Shale; Wales Heart Research Institute, Cardiff University, Cardiff, UK

\subsection{6/thoraxjnl-2013-204457.429}

Background Co-morbidities are of increasing importance in patients with COPD. However, the implications for function and health status have not been fully established. We hypothesised that the number of co-morbidities would relate to physical capacity, health status and impairments as measured by the comprehensive geriatric assessment (CGA) in COPD but not comparator subjects.

Method As part of the longitudinal Assessment of Risk in Chronic Airways Disease Evaluation (ARCADE), 500 patients with stable COPD (confirmed with spirometry) were compared to 141 comparator subjects (past or current smokers) free from respiratory disease. In all subjects previously diagnosed co-morbidities including; hypertension, hypercholesterolemia, angina, myocardial infarction, Stroke/TIA, atrial fibrillation, diabetes, and osteoporosis were recorded using a standardised health questionnaire. Spirometry, BMI, six minute walk distance (6MWD), the Timed Up and Go (TUG), and the number of impairments were determined using the CGA. Patients with COPD also completed the St George's Respiratory Questionnaire (SGRQ).

Results Patients and comparators were similar in age, gender and BMI, but differed in $\mathrm{FEV}_{1} \%$ predicted 59 (20) and 105 (14) respectively $(\mathrm{p}<0.01)$. Patients had more co-morbidities median (range) $2(0-6)$ than comparators $1(0-3)(\mathrm{p}<0.01)$. Of the patients, $24 \%$ had no co-morbidity, $54 \%$ had $1-2$ co-morbidities and $22 \%$ had over 3 co-morbidities, while $54 \%$ of comparators had no co-morbidities and 45\% had 1-2 co-morbidities ( $\mathrm{p}<$ 0.01). Patients also had more impairments (CGA score), reduced 6MWD and increased TUG (all $\mathrm{p}<0.001$ ). The number of comorbidities related to age, BMI, 6MWD, TUG, fibrinogen, the CGA and SGRQ and but not FEV 1 in patients with COPD, and only to CGA score in comparators (Table 1 ).

Conclusion The number of comorbidities in COPD related to physical function, health status and impairments, independent of lung disease. Early management of co-morbidities may improve outcomes in patients with COPD.

\begin{tabular}{|c|c|c|c|c|}
\hline & COPD & $p=$ & Comparator & $p=$ \\
\hline & $r_{s}$ & & $r_{s}$ & \\
\hline Age (years) & 0.209 & $<0.001$ & 0.119 & 0.161 \\
\hline $\mathrm{FEV}_{1} / \mathrm{FVC}(\mathrm{L})$ & -0.014 & 0.751 & 0.089 & 0.295 \\
\hline $\mathrm{FEV}_{1} \%$ predicted & -0.031 & 0.488 & 0.045 & 0.598 \\
\hline BMI $\left(\mathrm{kg} / \mathrm{m}^{2}\right)$ & 0.208 & $<0.001$ & 0.144 & 0.088 \\
\hline $6 \mathrm{MWD}(\mathrm{m})$ & -0.208 & $<0.001$ & -0.147 & 0.081 \\
\hline TUG (s) & 0.192 & $<0.001$ & -0.020 & 0.814 \\
\hline CGA score & 0.450 & $<0.001$ & 0.352 & $<0.001$ \\
\hline SGRQ total score & 0.147 & 0.001 & - & - \\
\hline
\end{tabular}

\section{M20 FINDING THE MISSING MILLIONS: CASE FINDING FOR COPD IN PEOPLE ATTENDING OTHER LONG TERM CONDITION CLINICS IN PRIMARY CARE}

DMG Halpin, S Holmes, J Calvert, D Mclnerney; NHS SW, Taunton, UK

\subsection{6/thoraxjnl-2013-204457.430}

Over $40 \%$ of people with COPD remain undiagnosed. Comorbidities are common in people with COPD but COPD is also a comorbidity of other long term conditions. As SHA respiratory leads in the SW we used this fact to develop a pilot programme to case find people with COPD among patients attending other long term clinics in primary care. The project was developed by the Leads and partially supported by Astra Zeneca, Boehringer Ingelheim, Chiesi \& Novartis who provided support for additional health care professional time, but it was also adopted by Bristol CCG.

Practices were asked to show all current or ex-smokers aged $\geq 35$ attending a long term condition clinic who were not known to have COPD a Patient Information Sheet and ask them to complete a questionnaire designed to help identify people with COPD (1). Patients were also asked to perform microspirometry using an ASMA-1 device, their age, height, \& smoking status were recorded. If they scored highly on the questionnaire and had an FEV1 below the lower limit of normal (LLN), their MRC breathlessness and CAT scores were recorded and they were offered further assessment within the practice to confirm the diagnosis. Smokers were offered referral to cessation services.

573 patients (323 men) were seen in 11 practices between Sep 2012 \& May 2013. Mean age 64.6 (range 36-90). 265 had high questionnaire scores and 115 of these also had FEV1 less than LLN-20\% of all patients seen. The mean FEV1 (\%pred) in these patients was 58.6 (range 5.5-77.6). 86 had an FEV 50$80 \%$ predicted, $2530-50 \%$ predicted. 44 had an MRC score of 0,13 of 1,44 of 2, 8 of 3 and 4 of 5. The mean CAT score was 
13.4 (range 2-40). 44 (38\%) were still smoking and 17 of these accepted referral to cessation services. 27 of the other 125 smokers assessed but not thought to have COPD also accepted referral.

Case finding using this method in people already attending primary care clinics has a high yield ( 1 in 5 ) takes little time and deserves wider adoption.

\section{REFERENCES}

1. Respiration 2006;73:285-95.

\section{M21 SPACE TO BREATHE: A NEW HOSPICE BASED PALLIATIVE CARE, RESPIRATORY AND PSYCHOLOGY PROGRAMME FOR PATIENTS WITH SEVERE COPD AND THEIR CARERS}

${ }^{1}$ SF Hudson, ${ }^{2} \mathrm{R}$ Colclough, ${ }^{1} \mathrm{~F}$ Campbell, ${ }^{2} \mathrm{~B}$ Pereira, ${ }^{1} \mathrm{~J}$ Leek, ${ }^{2} \mathrm{~A}$ Sullivan, ${ }^{1} \mathrm{C}$ Davies, ${ }^{1} \mathrm{C}$ Weir; ${ }^{1}$ Birmingham St Marys Hospice, Birmingham, West Midlands; ${ }^{2}$ University Hospitals Birmingham, Birmingham, West Midlands

10.1136/thoraxjn-2013-204457.431

Background People with severe COPD have a burden of symptoms, often greater than those with lung cancer and have unmet need (Gore and Brophy 2000). A local palliative care needs analysis was conducted across primary and secondary care. Gaps were identified in the management of anxiety, breathlessness, social isolation, advance planning and carer support. Patients had high comparative admission rate and length of stay. A team, including a psychologist, OT, palliative and respiratory medicine and physiotherapy and a palliative care CNS, developed and delivered the programme.. The programmes focus was behavioural change through psycho-education, exercise and relaxation, underpinned by CBT.

Method Referral was from acute respiratory service for those with at least 2 acute admissions in the previous 6 months, FEV1 of $<50 \%$ predicted and optimised medical management. They attended the hospice programme for 5 weeks with transport provided. Two programmes were completed with a total of 12 patients and 3 carers HADS and CATS were taken at week 1 and week 6. 6 month pre and post course admission data was collected.

Results Patients described; improvement in confidence and quality of life and improved management of their exacerbations. HADS and CATS remained unchanged. Initial data from programme 1 demonstrated reduction in total admissions from 7 to 4 and reduction in total bed days from 47 to 20, over a 6 month period.

Conclusions Patient evaluated improvement in function and quality of life and reduction in hospital bed days would suggested continuation of the programme with a change in quality of life measurement.

\section{REFERENCE}

Gore JM, Brophy CJ, Greenstone MA. How well do we care for patients with end stage chronic obstructive pulmonary disease? Thorax 2000; 55:1000

\section{M22 THE CHRONIC OBSTRUCTIVE PULMONARY DISEASE ASSESSMENT TOOL (CAT) IN PATIENTS ADMITTED TO HOSPITAL FOR EXACERBATION}

${ }^{1} \mathrm{KH}$ Hoyles, ${ }^{2} \mathrm{AS}$ Sheehan, ${ }^{2} \mathrm{DLF}$ Forrester, ${ }^{2} \mathrm{SJJ} J$ Johnson, ${ }^{2} \mathrm{AJK}$ Knox, ${ }^{2} \mathrm{CEB}$ Bolton; ${ }^{1}$ Respiratory Medicine, Nottingham University Hospital Trust, Nottingham, England;
${ }^{2}$ Nottingham Respiratory Research Unit (NRRU), University of Nottingham, City Hospital Campus, Nottingham, England

\subsection{6/thoraxjnl-2013-204457.432}

Background The COPD assessment tool (CAT) measures health status $^{1}$ and is responsive to change with pulmonary rehabilitation $^{2}$ and out-patient exacerbations of COPD (AECOPD) ${ }^{3}$. This study established i) CAT score at AECOPD hospital admission, ii) change during recovery and iii) CAT in relation to other outcome measures of COPD severity at stability.

Methods Consenting patients presenting to hospital with a clinical diagnosis of AECOPD self-completed the CAT and answered detailed history. Length of stay (LOS) was recorded. At four week follow-up assessment, the CAT score, MRC dyspnoea score, spirometry and six-minute walking distance (6MWD) were measured.

Results Of 153 patients recruited at admission, there were 5 inpatient deaths, all with a high $(>20)$ CAT on admission. Median LOS per admission CAT category was CAT10-20: 2.5 days; CAT21-30: 4 days; CAT31-40: 5 days.

89 subjects were reassessed at 4 weeks and 72 had a clinical diagnosis of COPD confirmed, Table 1. In these subjects, the mean $(95 \% \mathrm{CI})$ change in CAT score from admission was -7(-9, $5), \mathrm{p}<0.001$. Whilst $61 / 72$ had a high CAT score on admission, there remained $39 / 72$ with high score at follow-up. CAT score at follow-up was related to $6 \mathrm{MWD}, \mathrm{r}=0.34, \mathrm{p}<0.01$ but not to age or forced expiratory volume in one second $\left(\mathrm{FEV}_{1}\right) \%$ predicted.

Conclusion Despite marked improvement in CAT score with recovery from an AECOPD requiring hospital admission, a large proportion persist with high CAT scores at 4 weeks indicating poor health status. The CAT score offers prognostic information and adds another dimension to the COPD assessment.

\section{REFERENCES}

1. Jones PW et al. ERJ 2009:34(3):648-54

2. Dodd JW et al. Thorax 2011; 66(5):425-9

3. Mackay AJ et al. AJRCCM 2012;185(11):1218-24

Abstract M22 Table 1. Results for the 72 patients with confirmed COPD.

\begin{tabular}{ll}
\hline Gender Male: Female (n) & $49: 23$ \\
Age (years) Median (range) & $68(48-86)$ \\
Length of Stay (days) Median (range) & $3(1-20)$ \\
$6 \mathrm{MWD}(\mathrm{m})$ at 4 week follow-up Median (range) & $140(5-420)$ \\
$\mathrm{FEV}_{1} \%$ pred at 4 week follow-up Mean (SD) & $46(16)$ \\
MRC score at 4 week follow-up Median (range) & $4(1-5)$ \\
Admission CAT score Mean (SD) & $28(7)$ \\
Follow-up CAT score Mean (SD) & $21(8)$ \\
\hline
\end{tabular}

\section{M23 COPD EXACERBATIONS OF LONGER DURATION WORSENS HEALTH RELATED QUALITY OF LIFE}

GC Donaldson, AJ MacKay, R Singh, J Allinson, S Brill, JA Wedzicha; UCL, London, United Kingdom

\subsection{6/thoraxjnl-2013-204457.433}

Introduction Patient's quality of life is related to the frequency of COPD exacerbations [Seemungal et al AJRCCM 1998: 157: 1418-1422]. There is increasing interest in reducing the duration of exacerbations but little evidence that this benefits patient's quality of life. 